\title{
Climate change scenarios for impact assessment in Cuba
}

\author{
A bel Centella*, Tomás G utiérrez, M iriam Limia, Roger Rivero J aspe \\ Institute of M eteorology, A partado 17032, CP 11700 Habana 17, C uba
}

\begin{abstract}
Determining seasonal and regional patterns of climate change is in growing demand for the assessiment of the potential impacts on climate-related economic activities, such as agriculture or water resource management. This paper presents the results of the work done to determine possible patterns of $\mathrm{CO}_{2}$-induced climate change in Cuba based on the IPCC's best estimate of climate sensitivity and using IS92a and KYOTOAI emission scenarios. The climate change scenarios were prepared combining general circulation model (GCM) results and output from the MAGICC climate model. The results of this study show that the methodology and the GCMs selected provide a large range of regional climate change and guarantee that the climatic change scenarios developed can be applied to explore a wide spectrum of the potential climate changes in different environments and social sectors in Cuba.
\end{abstract}

KEY WORDS: Climate scenarios · Global climate change $\cdot$ Climate variability $\cdot$ M odels

\section{INTRODUCTION}

In Cuba, changes in the supply of rainfall, whether in total or in frequency, could have enormous consequences for the economic and environmental sectors. Climatic anomalies have always occurred in Cuba; however, during the last 4 decades important climatic variations have been observed. Naranjo \& Centella (1998) have shown that the climate of Cuba is becoming warmer. M ean annual temperature has increased almost $0.5^{\circ} \mathrm{C}$, with the warmest periods being in the 1980s and middle 1990s. This increment was mainly due to a very significant positive trend in minimum temperature, with a mean 'warming' of almost $1.4^{\circ} \mathrm{C}$. Another important fact was the significant (almost to $2^{\circ} \mathrm{C}$ ) observed decrease in diurnal temperature range.

Records of annual precipitation have not shown any significant variations for a long period of time. However, an important increase in winter rainfall and a slight negative trend of precipitation in summer have been recently observed. These contrary seasonal rainfall behaviors have been an important factor in the

*E-mail: abel@met.inf.cu significant increase in drought frequency since 1960 and suggest that changes are occurring in the annual precipitation variation pattern (Lapinel et al. 1993).

The above results agree with the significant warming of the low troposphere over the region ( $\mathrm{N}$ aranjo \& Centella 1996), supporting the idea of important changes in the climate background, which are consistent with significant variations in the circulation patterns of the Pacific-North American sector (Trenberth 1990).

The observed variations and trends in the climate of Cuba and the potential implications of climate change due to the enhancement of the greenhouse effect has caught the attention of politicians, businessmen, and the public at large. Although it may not be clear whether the observed climatic trends are related to human activities or whether they have some natural explanation, it is necessary to assess the potential implications of future climate changes for some environmental and social sectors.

Having ratified the United Framework Convention on Climate Change, the Cuban government is committed to assessing the degree of vulnerability of the sectors which are likely to be most impacted by climate change. To do this, it is necessary to develop a re- 
presentation of future climate conditions or climate change scenario. The term climate scenario is used instead of climate change prediction and has been defined by Viner \& Hulme (1992) as 'an internally consistent representation of future climate, that is constructed from methods based upon sound scientific principles, and that can be used to give an understanding of the response of environmental and social systems to future climate change'.

The goal of this study is to define the climate change scenarios for Cuba on the basis of different emission scenarios and general circulation models (GCMs). The results of the analysis will be used to assess the vulnerability in 6 environmental and social sectors of Cuba.

\section{METHODOLOGY}

Several methods exist for creating a climate scenario. They fall into the following classes: synthetic scenarios, analogue scenarios and scenarios obtained from GCMs or global climate models (Carter et al. 1993). Among these, the most widely accepted approach involves the use of results from GCM climate change experiments.

Results from GCMs can be linked to the output from simpler models to enable a wider range of assumptions about future greenhouse gas emissions, climate feedback, and climate sensitivities to be represented in the scenarios (Hulme 1996). The Climatic Research Unit (CRU) of the University of East Anglia has developed 2 such computer programs (MAGICC and SCENGEN) that can be used for scenario construction.

Climate change scenarios result from a 3-stage process: definition of a global greenhouse gas emission scenario; conversion of the emissions into a global warming projection; and association of the global warming projection with a regional pattern of climate change.

2.1. E mission scenario. Two emission scenarios were selected for this study. These are the IS92a scenario, defined by the IPCC in 1992 and later revised in 1995, and the KYOTOA1 scenario which was provided by CRU (Table 1). The IS92a is a mid-range estimate of future emissions, assuming only a very modest degree of policy intervention to reduce the emissions. Technical descriptions of its underlying assumptions are well documented (Leggett et al. 1992, IPCC 1996). The KYOTOA 1 scenario takes into account the Protocol (for Annex 1 countries) approved in the third session Conference of the Parties of the UN Framework Convention on Climate Change (UNFCCC) held in Kyoto, Japan, and it assumes major policy intervention. Although other scenarios are available, the IS92a and KYOTOA1 emission scenarios were adopted for 3 reasons. First, the International Negotiation Committee of UNFCCC uses IS92a as a reference scenario. Second, IS92a has been widely used in studies of impact assessment, facilitating the comparison of results. Third, KYOTOA 1 is a 'next to real' policy intervention (at least it is based on assumptions that could be more real in a short time than other intervention scenarios), and it is interesting to take a picture of future climate in Cuba based on this emission scenario.

2.2. G lobal warming projections. The global warming projections for IS92a and KYOTOAI scenarios were made using CRU's MAGICC model framework. MAGICC (Model for the Assessment of Greenhouse gas Induced Climate Change) is a software package that includes a number of gas cycle and radiative transfer models, a sea level rise model, and a 1-dimensional upwelling-diffusion climate model. A more detailed description of MAGICC is given by Wigley (1994, cited by Hulme et al. 1995). Version 2.3 of the M AGICC computer package was used in this study.

To estimate the average global warming and sea level rise, MAGICC converts the emissions of greenhouse gases into concentrations using a number of gas cycle models. Afterwards, the concentration is converted into radiative forcing using radiative transfer models. Then, the resulting total global-mean radiative forcing drives an upwelling-diffusion energy balance climate model to produce the global temperature and sea level change.

In MAGICC, there are various parameters that determine warming and sea level rise. The most important is the climate sensitivity $\left(\Delta T_{2 \times}\right)$, which is a measure of how the global temperature changes for a given radiative forcing. Using the IPCC best estimate $\Delta \mathrm{T}_{2 \times}=2.5^{\circ} \mathrm{C}$ and its low and high range values $\left(1.5\right.$ and $4.5^{\circ} \mathrm{C}$, respectively), the global warming values were computed for the IS92a and KYOTOA 1 emission scenarios; these values are given in Table 2 . It is important to note that the effect of sulphate aerosols was considered, assuming that $\mathrm{SO}_{2}$ emissions remain at 1990 levels. Fig. 1 shows

Table 1. Emissions of $\mathrm{CO}_{2}, \mathrm{CH}_{4}$ and $\mathrm{N}_{2} \mathrm{O}$ for selected years based on the assumptions of the IS92a and KYOTOA 1 scenarios

\begin{tabular}{|ccccccc|}
\hline Year & \multicolumn{3}{c}{ IS92a } & \multicolumn{3}{c|}{$\mathrm{KYOTOAI}$} \\
& $\mathrm{CO}_{2}(\mathrm{Pg})$ & $\mathrm{CH}_{4}(\mathrm{Tg})$ & $\mathrm{N}_{2} \mathrm{O}(\mathrm{Tg})$ & $\mathrm{CO}_{2}(\mathrm{Pg})$ & $\mathrm{CH}_{4}(\mathrm{Tg})$ & $\mathrm{N}_{2} \mathrm{O}(\mathrm{Tg})$ \\
\hline 1990 & 7.62 & 578.6 & 16.25 & 7.62 & 578.6 & 16.25 \\
2010 & 11.12 & 660.6 & 17.75 & 10.02 & 639.1 & 17.89 \\
2030 & 13.7 & 756.8 & 19.21 & 12.07 & 729.7 & 19.12 \\
2050 & 15.3 & 857.6 & 19.85 & 13.66 & 817.0 & 19.66 \\
2100 & 20.2 & 989.6 & 20.25 & 17.66 & 855.7 & 20.25 \\
\end{tabular}


Table 2. Global warming $\left({ }^{\circ} \mathrm{C}\right)$ with respect to the $1961-1990$ baseline for IPCC low, mid and high sensitivities based on IS92a and KYOTOA 1 emission scenarios at selected years

\begin{tabular}{|c|c|c|c|c|c|c|c|c|c|c|c|c|}
\hline \multirow{2}{*}{ Emission scenario } & \multicolumn{4}{|c|}{ Low } & \multicolumn{4}{|c|}{ Mid } & \multicolumn{4}{|c|}{ High } \\
\hline & 2010 & 2030 & 2050 & 2100 & 2010 & 2030 & 2050 & 2100 & 2010 & 2030 & 2050 & 2100 \\
\hline IS92a & 0.34 & 0.63 & 0.96 & 1.72 & 0.47 & 0.90 & 1.38 & 2.52 & 0.65 & 1.25 & 1.94 & 3.63 \\
\hline KYOTOA 1 & 0.32 & 0.58 & 0.87 & 1.53 & 0.45 & 0.83 & 1.25 & 2.25 & 0.61 & 1.15 & 1.77 & 3.26 \\
\hline
\end{tabular}

projected global temperature rise under the IS92a and KYOTOA 1 scenarios.

2.3. Climate change projection. The last stage in scenario construction involves the use of GCM simulations to project the necessary variables for impact assessment and their spatial pattern of change.

Projecting the climate change using GCM s requires large amounts of computer time to carry out simulations. If the spatial and temporal resolutions of the models increase, then the computer requirements also increase. So, due to the high computational cost, it is difficult to evaluate a large number of possible climate scenarios using GCMs. However, simple climate models (SCMs) are able to reproduce a global mean response to forcing that is similar to that which is produced by GCMs. They include all the important stateof-the-art knowledge as reported by the IPCC, including a $\mathrm{CO}_{2}$-fertilization feedback and negative forcing of sulphate aerosols and stratospheric ozone depletion (IPCC 1990, 1992, 1996). Because SCM s incorporate a simplified representation of the physical processes involved in the climate system, they are not very computer time consuming and can be used to address
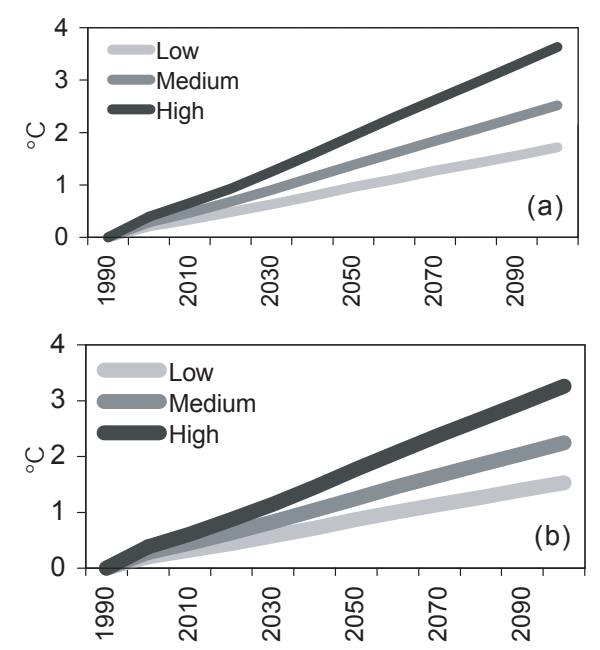

Fig. 1. Projected global temperature rise under (a) IS92a and (b) KYOTOA 1 emission scenarios with respect to 1961-1990. Low, medium, and high labels are associated with 1.5, 2.5, and $4.5^{\circ} \mathrm{C}$ climate sensitivity values, respectively different assumptions about greenhouse gas emission into the atmosphere. The IPCC Technical Report II (Houghton et al. 1997) offers a good description of SCMS used in the in the IPCC second assessment report and provides some examples of the SCMs' ability to reproduce GCM results.

SCM s do not project variables other than global temperatures and sea level, so it is necessary to combine the output of GCM s and the results of SCM s to generate a regional climate change pattern. To do this, the simulated change in climate at a gridpoint between the GCM control and $2 \times \mathrm{CO}_{2}$ simulations is divided by the respective GCM global warming to produce a standardized value that represents the regional change in any climate variable per degree of global warming. This standardized value is then multiplied by the global warming in a given year as given by the SCM. The process can be represented by:

$$
\Delta \mathrm{V}_{\mathrm{i}, \text { year }}=\Delta \mathrm{T}_{\text {year }} \mathrm{SCM} \times \Delta \mathrm{V}_{\mathrm{i}} / \Delta \mathrm{T}_{\mathrm{GCM}}
$$

where $\Delta V_{i}$ is the $2 \times \mathrm{CO}_{2}-1 \times \mathrm{CO}_{2} \mathrm{GCM}$ difference at gridpoint $\mathrm{i}, \Delta \mathrm{T}_{\mathrm{GCM}}$ is the GCM climate sensitivity, $\Delta \mathrm{T}_{\text {year }} \mathrm{SCM}$ is the global mean temperature change defined by the SCM for a given year with respect to 1990 , and $\Delta V_{i, \text { year }}$ is the gridpoint change in variable $V$ in the given year.

One important limitation of this approach is that regional climate changes are linearly related to changes in the average global temperature. It is unlikely that regional climates will actually behave in such a linear fashion.

In the present work, the computer-based program SCENGEN (developed by CRU) was used to both standardize the climatic variables and re-scale them using the average global warming projected by MAGICC to occur by 2010, 2030, 2050, and 2100 under IS92a and KYOTO1 emission scenarios.

Among the 14 GCMs available in SCENGEN, the results of the HADCM2 (Mitchell et al. 1995) and UKTR (Murphy \& Mitchell 1995) transient experiment models and the Oregon State University (OSU) (Schlesinger \& Zhao 1989) equilibrium experiment model were chosen. HADCM 2 is regarded as one of the leading models in the world, it has the largest global monthly mean precipitation pattern correla- 


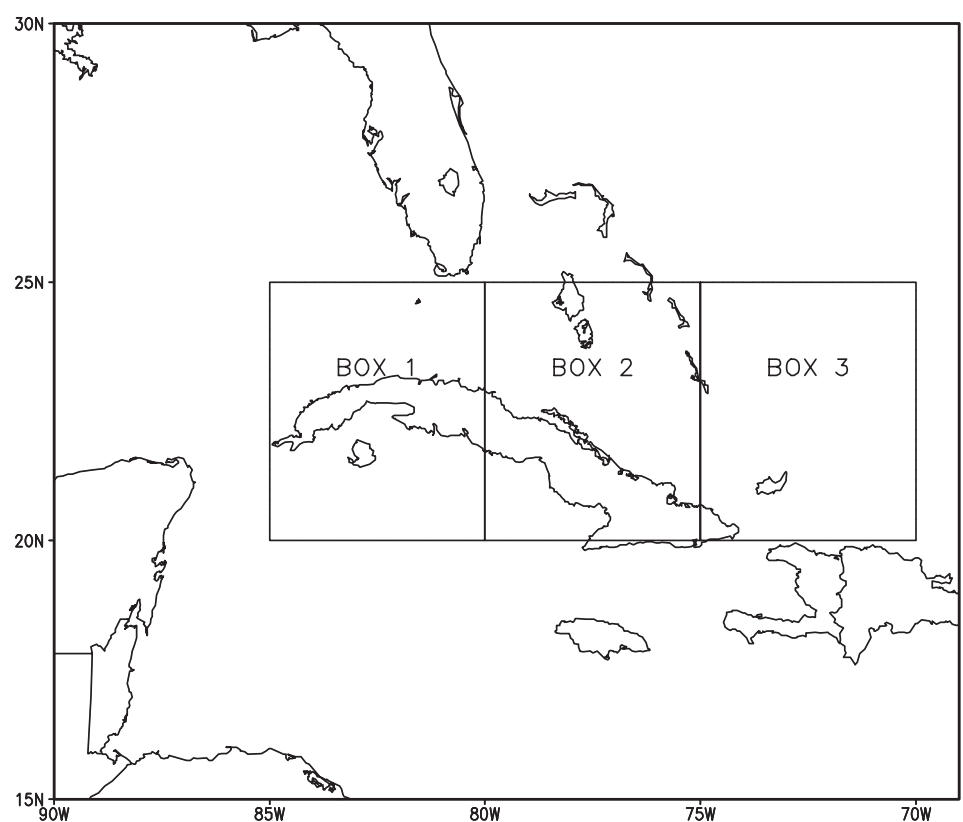

Fig. 2. The three $5^{\circ} \times 5^{\circ}$ latitude-longitude SCENGEN grid boxes that fall over Cuba

tion coefficient (0.77), and the projections provided by it agree in some sense with the observed climatic trend in the climate of Cuba. UKTR has been broadly used for impact assessment studies in different countries, so the results can be compared. The rainfall change produced by the OSU model is the highest for the Cuban region, thus providing the possibility to consider other possible climate change conditions.

Fig. 2 shows the 3 relevant $5^{\circ} \times 5^{\circ}$ latitude-longitude SCENGEN grid boxes that fall over Cuba. The climate change values for these grid boxes was applied to the Cuban baseline climatology to obtain the estimated future temperature and rainfall patterns under the emission scenarios selected.

\section{RESULTS}

As it is desirable for climate change scenario generation, the $3 \mathrm{GCM}$ models can provide a range of regional changes according to the uncertainties of both future climate and regional results of GCMs. Fig. 3 shows the changes in average annual temperature and rainfall for the 2050 (with respect to the 1961-1990 period). From this it is clear that the largest temperature increases are projected by the HADCM 2 and OSU models, which represent stronger drying and wetting conditions, respectively. The UKTR model reflects a more moderate temperature and precipitation change.

\subsection{HADC M 2 climate scenario}

A common characteristic of the HADCM 2derived climate scenario under the IS92a assumptions is an increase of temperature and a reduction of rainfall in the annual values. The largest increase of temperature is observed in the eastern half of Cuba (Boxes 2 and 3 ), while the more important reduction of precipitation and cloud cover occurs over the western half of the country (Box 1). Only for 2100 is the cloud cover reduction greatest in the eastern part of Cuba.

The annual variation pattern (see Figs. $4 \& 5$ for examples of 2050) reflects another important fact: The greatest warming combined with significant reductions of rainfall occurs in summer. This indicates the occurrence of a warmer and drier climate than at present. At the end of autumn and beginning of winter, the pattern changes, and an important rainfall rise is observed. The reduction of rainfall is around 10 to $15 \%$ in the spring and summer months (except April), while an important positive change (about 15 to $20 \%$ ) is observed for November and December. For all grid boxes, the greatest warming in mean surface air temperature

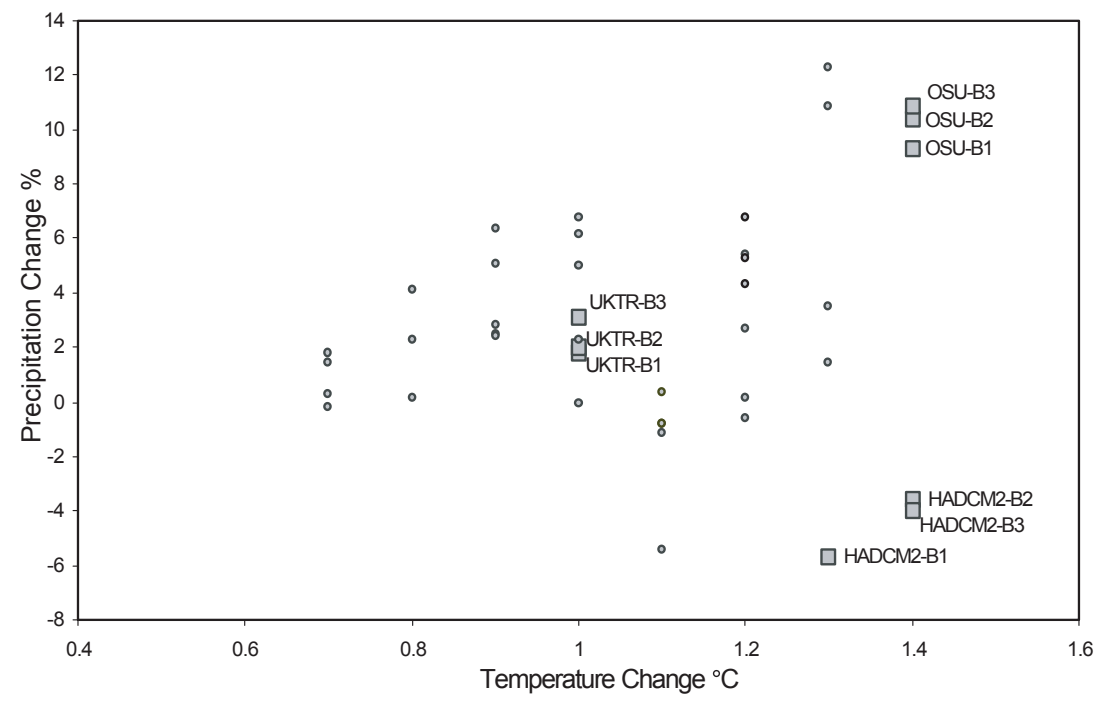

Fig. 3. Changes in average annual temperature and rainfall for the 2050 for 14 GCM experiments for each SCENGEN grid box over Cuba. The 3 experiments used in this work are indicated. B1, B2 and B3: Boxes 1, 2, and 3, respectively 

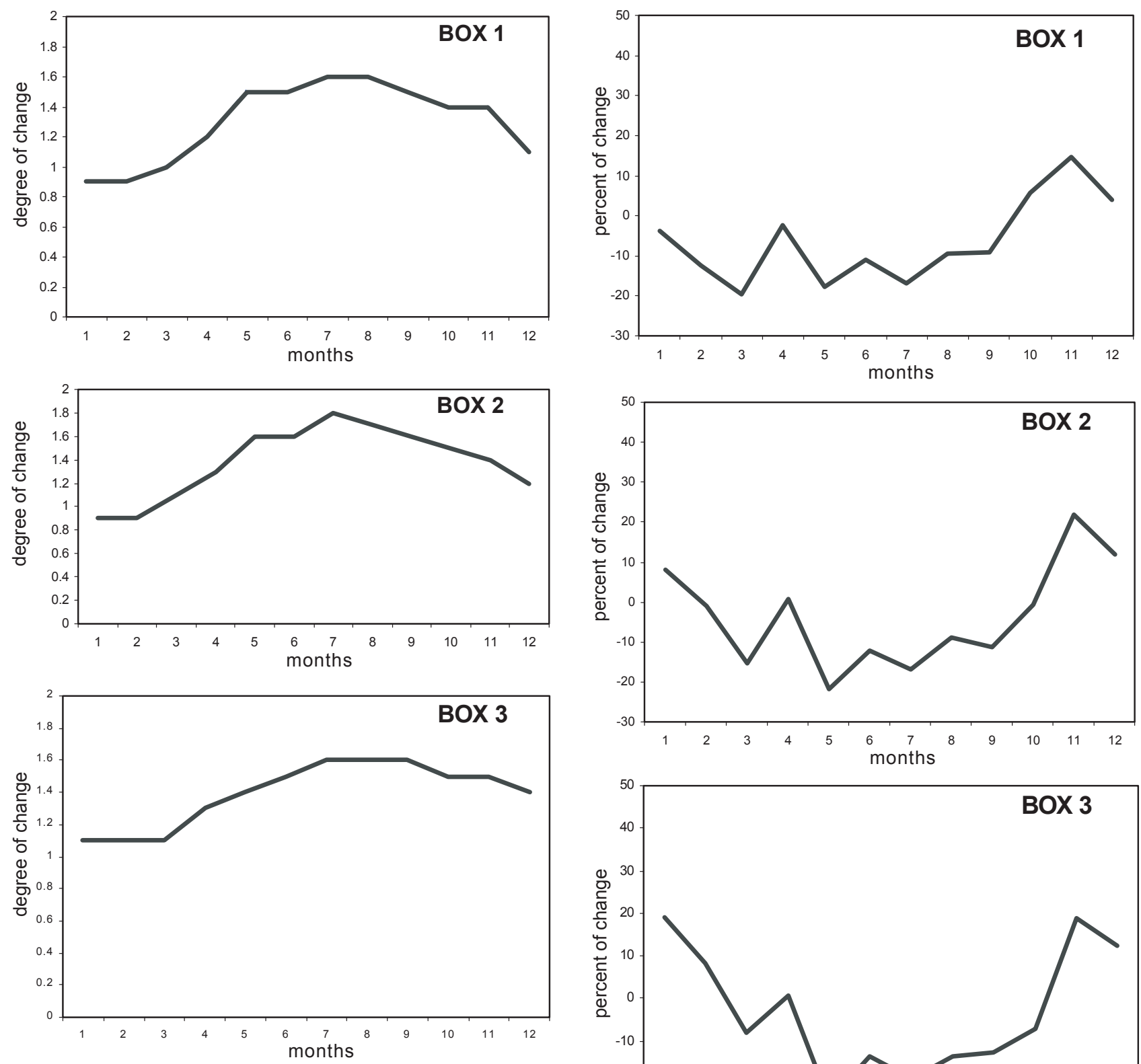

Fig. 4. Changes in annual temperature $\left({ }^{\circ} \mathrm{C}\right.$ ) in 2050 (with respect to 1961-1990) for the HADCM2-derived climate change scenario under IS92a

occurs from May to November (between 1.4 and $1.6^{\circ} \mathrm{C}$ ) and a decrease of about $0.9^{\circ} \mathrm{C}$ occurs in J anuary and February.

For the KYOTOA 1 emission scenario, the results are little different from IS92a, and the projected climate change has similar annual variation patterns. As expected, temperature change is less than for IS92a, but the reduction is no more than 0.2 or $0.4^{\circ} \mathrm{C}$ (Table 3). For rainfall, the patterns are similar, although under KYOTOA1 the reduction of rainfall during summertime is small.

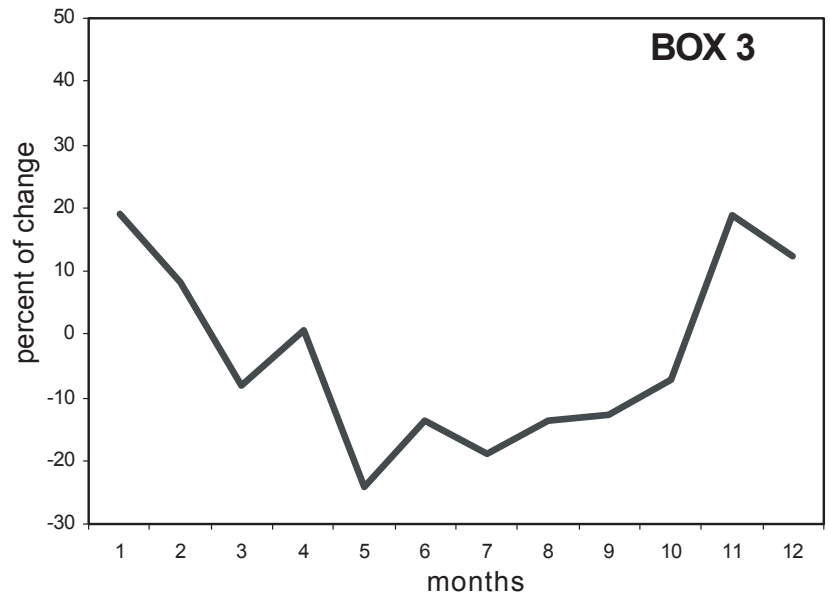

Fig. 5. Percentage change in annual rainfall in 2050 (with respect to 1961-1990) for the HADCM2-derived climate change scenario under IS92a

\subsection{UKTR and OSU climate change scenarios}

As mentioned earlier, there is a considerable uncertainty about the regional results of GCMs, so it is important to consider alternative patterns of climate change that could also be possible. The evaluation of these alternative scenarios can be used to avoid the 
Table 3. Annual climate change generated with the HADCM 2 model under the IS92a and KYOTOA1 emission scenarios

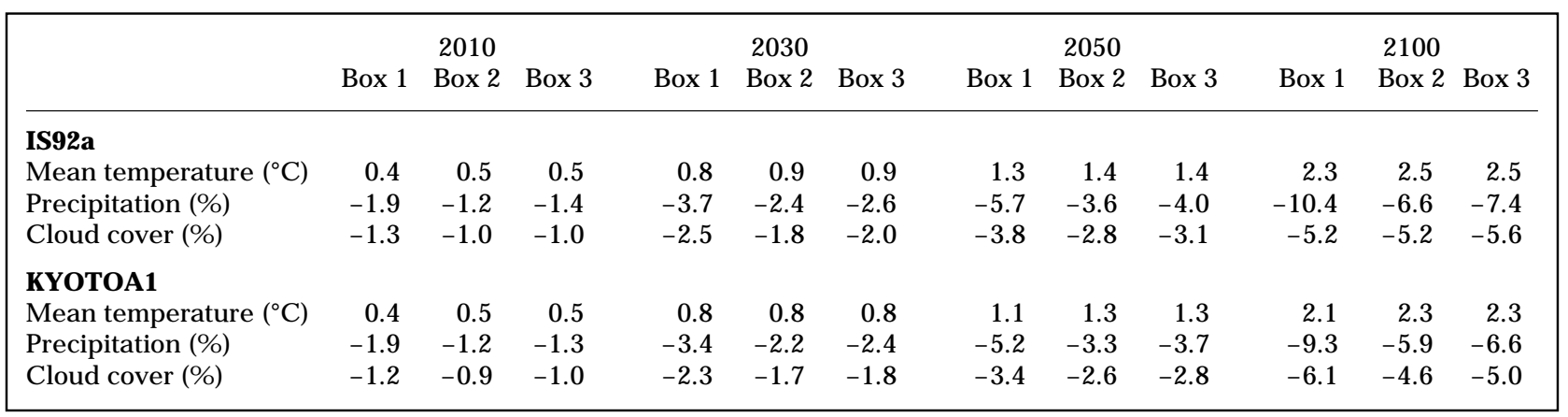

Table 4. Annual climate change generated with the OSU and UKTR models under the IS92a and KYOTOA 1 emission scenarios

\begin{tabular}{|c|c|c|c|c|c|c|c|c|c|c|c|c|}
\hline & \multicolumn{3}{|c|}{2010} & \multicolumn{3}{|c|}{2030} & \multicolumn{3}{|c|}{2050} & \multicolumn{3}{|c|}{2100} \\
\hline & Box 1 & Box 2 & Box 3 & Box 1 & Box 2 & Box 3 & Box 1 & Box 2 & Box 3 & Box 1 & Box 2 & Box 3 \\
\hline \multicolumn{13}{|l|}{ UKTR based on IS92a } \\
\hline M ean temperature $\left({ }^{\circ} \mathrm{C}\right)$ & 0.3 & 0.3 & 0.3 & 0.6 & 0.6 & 0.6 & 1.0 & 1.0 & 1.0 & 1.8 & 1.8 & 1.8 \\
\hline Precipitation (\%) & 0.6 & 0.7 & 1.1 & 1.2 & 1.3 & 2.0 & 1.8 & 2.0 & 3.1 & 3.3 & 3.6 & 5.6 \\
\hline Cloud cover $(\%)$ & -2.3 & -2.2 & -1.7 & -4.5 & -4.1 & -3.2 & -6.9 & -6.4 & -4.9 & -12.6 & -11.6 & -8.9 \\
\hline \multicolumn{13}{|l|}{ OSU based on IS92a } \\
\hline M ean temperature $\left({ }^{\circ} \mathrm{C}\right)$ & 0.5 & 0.5 & 0.5 & 0.9 & 0.9 & 0.9 & 1.4 & 1.4 & 1.4 & 2.5 & 2.5 & 2.5 \\
\hline Precipitation (\%) & 3.2 & 3.5 & 3.7 & 6.1 & 6.8 & 7.1 & 9.3 & 10.4 & 10.9 & 17.0 & 19.0 & 19.9 \\
\hline Cloud cover $(\%)$ & -1.0 & -1.2 & -1.5 & -2.0 & -2.4 & -2.9 & -3.0 & -3.6 & -4.4 & -5.5 & -6.6 & -8.1 \\
\hline \multicolumn{13}{|c|}{ UKTR based on KYOTOAI } \\
\hline M ean temperature $\left({ }^{\circ} \mathrm{C}\right)$ & 0.3 & 0.3 & 0.3 & 0.6 & 0.6 & 0.6 & 0.9 & 0.9 & 0.9 & 1.6 & 1.6 & 1.6 \\
\hline Precipitation (\%) & 0.6 & 0.6 & 1.0 & 1.1 & 1.2 & 1.9 & 1.6 & 1.8 & 2.8 & 3.0 & 3.2 & 5.0 \\
\hline Cloud cover $(\%)$ & -2.2 & -2.1 & -1.6 & -4.1 & -3.8 & -2.9 & -6.2 & -5.8 & -4.4 & -11.2 & -10.4 & -8.0 \\
\hline \multicolumn{13}{|l|}{ OSU based on KYOTOA1 } \\
\hline M ean temperature $\left({ }^{\circ} \mathrm{C}\right)$ & 0.5 & 0.4 & 0.5 & 0.8 & 0.8 & 0.8 & 1.3 & 1.2 & 1.3 & 2.3 & 2.2 & 2.3 \\
\hline Precipitation (\%) & 3.0 & 3.4 & 3.6 & 5.6 & 6.3 & 6.5 & 8.4 & 9.4 & 9.9 & 15.2 & 17.0 & 17.8 \\
\hline Cloud cover $(\%)$ & -1.0 & -1.2 & -1.4 & -1.8 & -2.2 & -2.7 & -2.8 & -3.3 & -4.0 & -4.9 & -5.9 & -7.2 \\
\hline
\end{tabular}

inappropriate understanding that a projection could be interpreted as a prediction.

The alternative scenarios were created using the UKTR and OSU climate models. Table 4 shows the temperature, precipitation, and cloud cover annual changes for these alternative scenarios. The OSU model results indicate an increase in temperature of similar magnitude to HADCM 2 and an important increase in precipitation. In the cases of UKTR, the changes in both temperatures and precipitation are minor.

Figs. $6 \& 7$ show the annual variation patterns of temperature and precipitation projected to occur by 2050. For temperature, a significant increase is projected by the OSU model mainly at the beginning of the year, with the values ranging from 1.4 to $1.7^{\circ} \mathrm{C}$. In summer, the temperature change indicated by this model is less than that projected by HADCM 2, which represents a more intensive warming for this season. As was noted earlier, the UKTR temperature projection is the lowest and its annual variation pattern shows little change. It should be noted that the 3 model projection patterns are similar from October to December, at least for Boxes 1 and 2.

\section{DISCUSSION AND CONCLUSIONS}

In the study of future climate conditions for various $30 \mathrm{yr}$ periods of the next century, considerable changes are possible in Cuba. Although the agreement between models is low for rainfall projections and only the OSU model produced a large increase in annual precipitation, rising ambient temperatures will probably increase evapotranspiration rates and reduce the availability of water (Hulme et al. 1994). So, for these climate conditions, a reduction of vegetal and animal biomass would be an important impact. Note that Coe et al. (1976) demonstrated that there is a positive correlation between vegetation production and rainfall. 

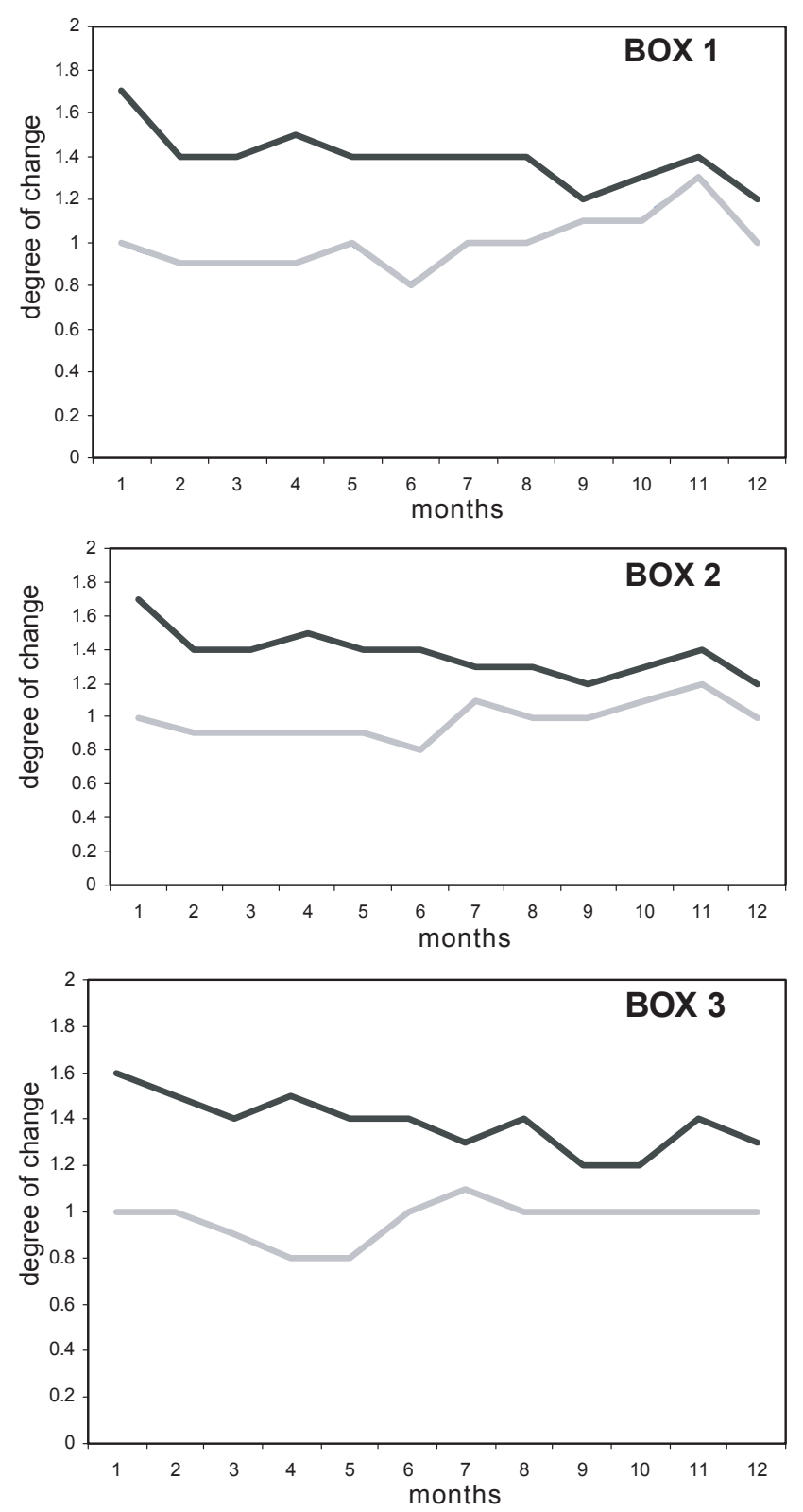

Fig. 6. Changes in annual temperature $\left({ }^{\circ} \mathrm{C}\right)$ in 2050 (with respect to 1961-1990) for the UKTR (gray) and OSU (black) alternative scenarios under the IS92a emission scenario

The HADCM 2 projected annual precipitation variation is similar to the observed trend in the annual rainfall variation pattern for the last $30 \mathrm{yr}$ (reduction in wet season and increase in dry season). Thus, the apparent trend to a redistribution of monthly rainfall around the year pointed out by Naranjo \& Centella (1998) could be continued under this scenario. It suggests a possible intensification of the drought occurrence with respect to the 1961-1990 period.

Environmental problems, such as desertification and biodiversity loss, could increase or appear in regions
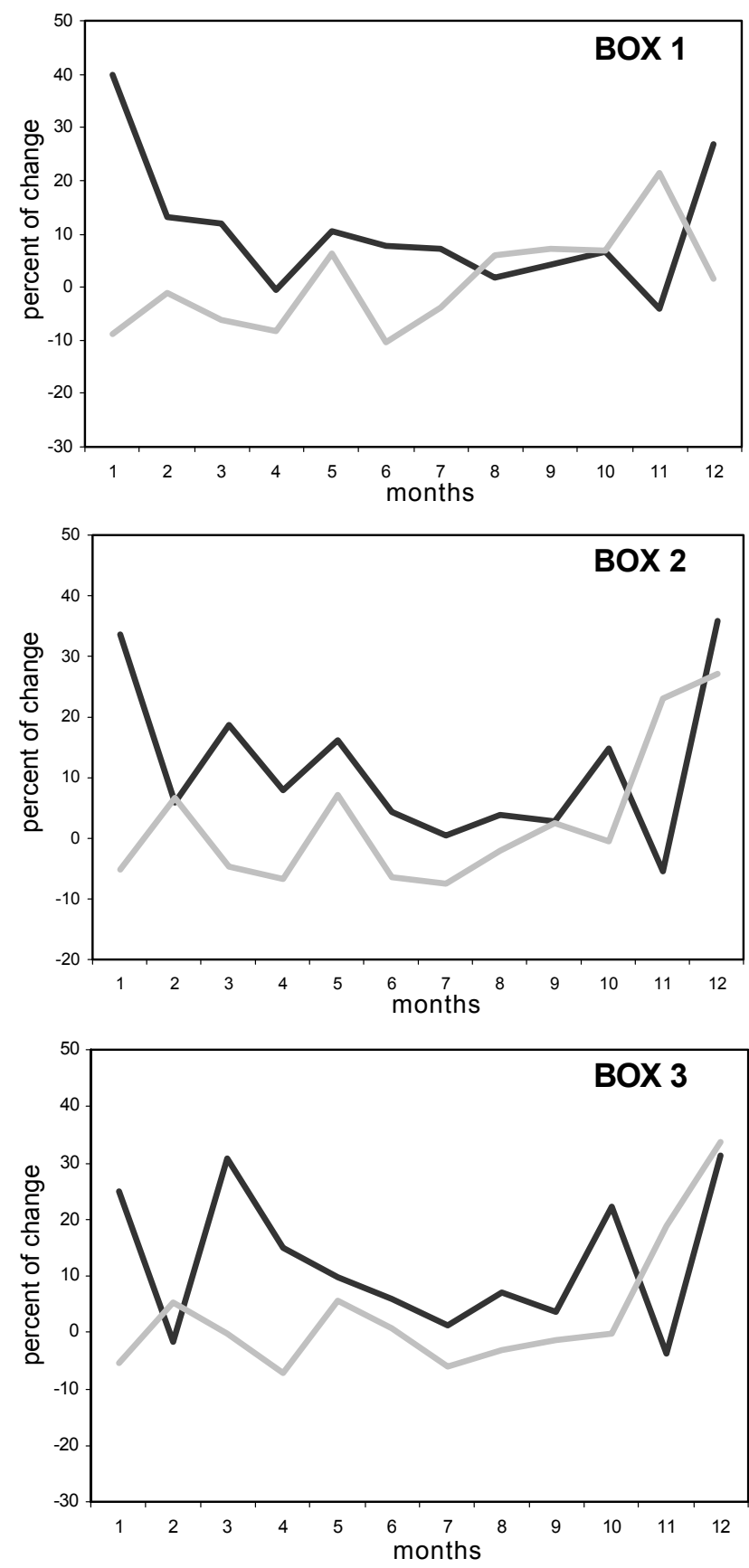

Fig. 7. Percentage change in rainfall in 2050 (with respect to 1961-1990) for the UKTR (gray) and OSU (black) alternative scenarios under the IS92a emission scenario

where high temperature and very low precipitation coexist in space and time. An example of these areas is the portion of the country that lies in Box 3. In recent years, the south coast of this region has been continually affected by environmental problems caused, in some manner, by the combination of high temperatures and very little rain throughout the year. So, the possible rainfall reduction could reinforce the present 
problems in this zone (for example, increased damage due to desertification).

For the HADCM 2-derived climate change scenario, the picture of future climate under the 2 emission scenarios was somewhat similar. For the KYOTOA 1 scenario, a 0.2 or $0.4^{\circ} \mathrm{C}$ reduction in warming was the major difference with respect to the IS92a scenario. In the case of rainfall, both the spatial and annual variations were very similar.

Alternative scenarios show, in general terms, a future climate change under $2 \times \mathrm{CO}_{2}$ conditions that implies a temperature increase of 1 to $2.5^{\circ} \mathrm{C}$ for 2050 and 2100, depending on the GCM being used. Notwithstanding that the reliability of precipitation simulation is not high, one important fact is that all of the GCMs considered in this work tend to produce a rainfall increase in some winter months of more than $15 \%$. This fact agrees in some sense with the observed winter precipitation trend in Cuba and could suggest that the current rise in the frequency of heavy rainfall (which is an important cause of the observed winter precipitation increase) could be continued or intensified. Rainfall is an important natural resource for Cuba, so theses scenarios are very important for assessing both the potential impact of climate change and the vulnerability of the country.

The climate change scenarios presented here were generated for 4 selected $30 \mathrm{yr}$ periods assuming midrange climate change sensitivity $\left(2.5^{\circ} \mathrm{C}\right)$. However, depending on how sensitive the climate system is to a given forcing, the changes will occur sooner or later. For example, considering only the results for 2050 and assuming a value for climate sensitivity of $4.5^{\circ} \mathrm{C}$ (very sensitive), changes for the 'main' and alternative scenarios could occur as early as 2034. Alternatively, if the climate sensitivity is low $\left(1.5^{\circ} \mathrm{C}\right)$ then the changes may not be fully realized until 2078.

\section{LITERATURE CITED}

Carter T, Holopainen E, Kannien M (1993) Techniques for developing regional climatic scenarios for Finland. Report of an International Workshop, Espoo. Painatuskeskus, Helsinki

Coe MJ , Cumming DHM, Phillipson J (1976) Biomass production of Africa herbivores in relation to rainfall and primary production. Oecologia 22:341-354

Houghton JT, Meira Filho LG, Griggs DJ , Maskell K (1997)
An introduction to the simple climate models used in the IPCC second assessment report. IPCC Technical paper II. IPCC, Geneva

Hulme M (1996) Climate change and Southern Africa: an exploration of some potential impacts and implications in the SADC region. Breckland Print Limited, N orfolk

Hulme M, Conway D, Kelly PM, Subak S, Downing TE (1994) The impacts of climate change on Africa. Center for Social and Economic Research on Global Environment Working Paper GEC 95-04, University of East Anglia (UEA), Norwich

Hulme M, J iang T, Wigley T (1995) A climate change scenario generator: a user manual. Climatic Research Unit, UEA, Norwich

IPCC (Intergovernmental Panel on Climate Change) (1990) Climate change: the IPCC scientific assessment. Houghton J T, J enkins GJ , Ephiraums J J (eds). Report of Working Group I of the IPCC. Cambridge University Press, Cambridge

IPCC (1992) Climate change 1992: the supplementary report to the IPCC scientific assessment. Houghton JT, Callander BA, Varney SK (eds). Cambridge University Press, Cambridge

IPCC (1996) Climate change 1995: the science of climate change. Houghton J T, M eira Filho LG, Callander BA, Harris $M$, Kattenburg A, Maskell $K$ (eds). Cambridge University Press, Cambridge

Lapinel B, Rivero RE, Cutié V (1993) Las sequías en Cuba en el período 1931-1990. Research Report, Institute of M eteorology of Cuba, Havana

Leggett J, Pepper WJ , Swart RJ (1992) Emissions scenarios for the IPCC: an update. In: Houghton J T, Callander BA, Varney SK (eds) Climate change 1992: the supplementary report to the IPCC scientific assessment. Cambridge University Press, Cambridge, $\mathrm{p}$ 75-95

M itchell J FB, J ohns TC, Gregory J M, Tett SFB (1995) Climate response to increasing levels of greenhouse gases and sulphate aerosols. Nature 376:501-504

Murphy J M, Mitchell J FB (1995) Transient response of the Hadley Centre coupled ocean-atmosphere model to increasing carbon dioxide. Part 2. Spatial and temporal structure of the response. J Clim 8:57-80

Naranjo LR, Centella A (1996) Interannual variations in the meteorological fields over the Caribbean and Gulf of M exico. I Part: Sea level pressure and $500 \mathrm{hPa}$. heights. Scientific Report. National Climate Center, Institute of M eteorology of Cuba, Havana

Naranjo LR, Centella A (1998) Recent trends in the climate of Cuba. Weather 53:78-85

Schlesinger ME, Zhao ZC (1989) Seasonal climatic change introduced by doubled $\mathrm{CO}_{2}$ as simulated by the OSU atmospheric GCM/mix-layer ocean model. J Clim 2: 429-495

Trenberth (1990) Recent observed interdecadal climate changes in the northern hemisphere. Bull Am Meteorol Soc 71:988-993

Vinner D, Hulme M (1992) Climate change scenarios for impact studies in the UK. Climatic Research Unit, UEA, Norwich 